\title{
LASERTERAPIA DE BAIXA POTÊNCIA NA REVERSÃO DO ANESTRO PUERPERAL EM VACA EM AMAMENTAÇÃO
}

\author{
Low Power Lasertherapy in Anestrus Puerperal \\ Reversion in Cow in Lactation
}

\begin{abstract}
Silvana Massuqueto
Médica Veterinária da PUCPR, Curitiba - PR. e-mail: silvana.massuqueto@pucpr.br
\end{abstract}

Ivonete do R. Pereira

Médica Veterinária, Residente da PUCPR, São José dos Pinhais - PR. e-mail: ivonete.pereira@uol.com.br

Claudia Regina Vieira Rocha Coeli

Médica Veterinária da PUCPR, Curitiba - PR. e-mail: pelos.penas@uol.com.br

Marcio Saporski Segui

Médico Veterinário, Prof. da PUCPR, Curitiba - PR. e-mail: marcio.segui@pucpr.br

Marco Antonio Ferrari

Mestrando em Bioengenharia em Laser da USP-IPEN. São Paulo - SP. e-mail: m-ferrari@uol.com.br

\section{Resumo}

Diversos estudos têm avaliado a influência da terapia a laser de baixa potência em tecidos biológicos. O laser, operando com baixa potência, tem sido empregado em Medicina Veterinária visando a ação terapêutica sobre os diferentes tecidos orgânicos, com ênfase no tratamento da dor, inflamação, regeneração e circulação, com possíveis reabilitações sensoriais, locomotoras e reprodutivas. Objetivando ampliar os conhecimentos na área, buscou-se avaliar a inter-relação da luz laser infravermelha em células do tecido ovariano. Ovários inativos de uma vaca da raça holandesa preta e branca amamentando (peso de $300 \mathrm{~kg}$ e escore da condição corporal 1,5) foram submetidos ao tratamento de laserterapia com diferentes potências de irradiação, variando entre 10 e $50 \mathrm{~mW}$, até a retomada da atividade ovariana com ovulação. O restabelecimento da função ovariana foi acompanhado por exames ultra-sonográficos diários e palpação retal dos ovários, executados durante quatorze dias, obedecendo a uma seqüência de cinco dias seguidos de laserterapia, por dois dias de descanso. Ocorreu a reversão do anestro puerperal no $18^{\circ}$ dia de tratamento, ao ser observado um novo corpo lúteo no ovário direito. Os resultados demonstraram a influência da laserterapia de baixa potência sobre o estroma ovariano, constituindo-se em uma nova abordagem terapêutica na área reprodutiva.

Palavras-chave: Laserterapia; Laser de baixa potência; Bovino; Reversão de anestro puerperal; Ovários. 


\begin{abstract}
Several studies have been evaluated the influence of the low power laser therapy in biological tissues. The laser operating in low power has been used in Veterinary Medicine, seeking the therapeutic action on different organic tissues, with emphasis in the treatment of pain, inflammation, regeneration and circulation, with possible sensorial, locomotor and reproductive rehabilitations. In order to increase the knowledge in this area, we looked to evaluate the interrelation of the infrared laser light in cells of the ovarian tissue. Inactive ovaries of a black and white Holstein cow in lactation (weight of $300 \mathrm{~kg}$ and corporal score 1.5) were submitted to laser therapy treatment at different irradiation power levels, varying between 10 and $1000 \mathrm{~mW}$, until the returning of the ovarian activity with ovulation. The re-establishment of the ovarian function was accompanied by daily ultrasound exams and rectal palpation of the ovaries, carried out during fourteen days, following a sequence of five days of laser therapy and two days of rest. The reversion of the puerperal anestrus took place at the 18 th day of treatment, when a new corpus luteum was observed in the right ovary. The results demonstrated the influence of the low power laser therapy on the ovarian stroma, being a new therapeutic approach in the reproductive area.
\end{abstract}

Keywords: Laser therapy; Low power laser; Bovine; Reversion of anestrus puerperal; Ovaries.

\title{
INTRODUÇÃO
}

A luz laser infravermelha constitui-se em uma inovação tecnológica com impacto sobre várias áreas. A obtenção de radiação laser a partir de diferentes substâncias (meios ativos) gerou um considerável número de diferentes tipos de laser, tais como laser de $\mathrm{CO}_{2}$, Argônio, Arsenito de Gálio, Hélio-Neônio, Diodo emissor e, conseqüentemente, um significativo número de diferentes aplicações. A rigor, o fato assume proporções gigantescas, na medida em que se considera a existência de um emissor de laser, como uma forma de manipulação da matéria em níveis extremamente íntimos. Ao desenvolver o laser, o homem, por meio de recursos tecnológicos, alcançou níveis subatômicos, manipulando estruturas menores que a menor estrutura observável (VEÇOSO, 1993).

O termo laser constitui-se numa sigla (Light Amplification by Stimulated Emission of Radiation), ou seja, Amplificação da Luz por Emissão Estimulada de Radiação (VEÇOSO, 1993). Amplificação da lur: a radiação laseré constituída por ondas eletromagnéticas, visíveis ou não, de acordo com o seu comprimento de onda. O caráter de amplificação explica-se pela elevada concentração de energia, que aporta, conseqüentemente, ao grande número de fótons, dos quais é constituída. Emissão estimulada de radiação: $\mathrm{O}$ fenômeno da emissão estimulada constitui-se na emissão de luz a partir da estimulação da matéria, pelo fornecimento de energia aos átomos (VEÇOSO, 1993).

Segundo Baxter (1998), ocorre absorção da radiação quando um fóton de luz interage com um átomo ou molécula, em que a diferença em termos de energia das bandas de valência equivale à energia transportada pelo fóton. Isso acarreta duas conseqüências: para um fóton de determinada energia quântica - e, portanto, de determinado comprimento de onda - apenas certas energias quânticas serão capazes de absorver a radiação luminosa; por outro lado, para determinada molécula, apenas certas energias quânticas podem ser passíveis de absorção, denominando-se de espectro de absorção para a molécula. Deste modo, diz-se que a absorção é específica para o comprimento de onda. Esse é um conceito importante nas aplicações da laserterapia de baixa potência (LLLT), porquanto esta especificidade de absorção para o comprimento de onda, efetivamente, determina qual o tipo de tecido que irá absorver preferencialmente a radiação incidente e por sua vez a profundidade de penetração de um determinado instrumento de terapia.

De acordo com Carci (2003), a irradiação laser é composta por fótons que transportam e transferem energia ao aplicá-la em qualquer superfície. Com a aplicação dessa energia, obtêm-se efeitos diretos ou primários (efeitos bioquímicos, bioelétricos, bioenergéticos), indiretos (estímulo à microcirculação 
sanguínea, estímulo trófico celular) e terapêuticos (analgesia, antiinflamatório, antiedema, estimulante de trofismo tecidual). Geralmente, na laserterapia, utilizam-se emissores com comprimentos de onda entre $600 \mathrm{~nm}$ e $1100 \mathrm{~nm}$, pois comprimentos de onda inferiores a $600 \mathrm{~nm}$ e superiores a $1100 \mathrm{~nm}$ são fortemente absorvidos pela pele, reduzindo-se, por conseqüência, a profundidade de penetração.

Para que a radiação laser produza algum efeito, é necessário que ela seja absorvida, ou seja, deve haver uma interação dessa radiação com as estruturas moleculares e celulares do organismo (VEÇOSO, 1993). A luz laser interage com um tecido biológico de quatro formas: parte da luz pode ser refletida ao incidir no organismo, parte da radiação emitida será refletida e, conseqüentemente, não será absorvida; parte da luz pode ser transmitida pelo tecido sem atenuação e parte da luz remanescente pode ser absorvida pelos componentes do tecido, levando, nesse caso, à transferência de energia para o tecido, pertinente aos processos ressonantes. Finalmente, pode ser espalhada ou difundida dentro do tecido (VEÇOSO, 1993; MALDONADO, 2003). Uma vez que os tecidos são principalmente constituídos por água, a absorção da luz por ela é de fundamental importância para aplicações biomédicas. Os elementos do tecido que exibem um alto coeficiente de absorção de um peculiar comprimento de onda, ou por uma região do espectro, são chamados cromóforos. Além da água, cromóforos, como a melanina, a hemoglobina, as proteínas e, no caso de tecidos dentais duros, a hidroxiapatita, exercem influência significante sobre a interação da radiação e o tecido (MALDONADO, 2003).

A grandiosidade está justamente na manipulação do infinitamente pequeno e igualmente na possibilidade de utilização dos frutos desta manipulação em benefício dos animais, algo que, embora fruto da tecnologia, assume características de natural, por ser originário da natureza. Cada vez mais a terapia a laser vem conquistando espaço na medicina veterinária, com pesquisas que buscam inovações e respostas breves em tratamentos (VEÇOSO, 1993).

O objetivo desta pesquisa foi avaliar a atividade ovariana de um animal em anestro puerperal submetido à laserterapia de baixa potência.

\section{MATERIAIS E MÉTODOS}

A pesquisa foi conduzida na Fazenda Experimental Gralha Azul, da Pontifícia Universidade Católica do Paraná, localizada no município de Fazenda Rio Grande, Paraná. Foi utilizado um animal, espécie bovina, fêmea, raça Holandesa Preta e Branca, com escore da condição corporal 1,5, de acordo com a escala de 1 a 5, segundo critérios de Edmondson, Lean e Weaver (1989), idade de 4 anos e peso de $300 \mathrm{~kg}$, encontrando-se no $55^{\circ}$ dia pós-parto e amamentando dois bezerros.

As aplicações da laserterapia foram realizadas diariamente em ambos os ovários, por 40 segundos com laser de diodo (comprimento de onda (ë), entre 790 e $808 \mathrm{~nm}$ ), marca Prisma, operando em doses de 1 a $20 \mathrm{~J} / \mathrm{cm}^{2}$ e com potências variáveis entre 10 e $1000 \mathrm{~mW}$, com 14 aplicações, sendo que a cada 5 dias havia a interrupção do tratamento de dois dias (final de semana), retomando-se em seguida o tratamento, de acordo com a Tabela 1.

O animal permaneceu em piquete, com alimentação baseada em ração para bovinos leiteiros associada à silagem e sal mineral ad libitum, amamentando simultaneamente dois bezerros durante a execução do experimento. As mensurações dos ovários, bem como a atividade ovariana, foram realizadas no período vespertino por meio de ultra-sonografia transretal, com transdutor de $5 \mathrm{MHz}$ modo $\mathrm{B}$ e registradas pelo vídeo printer. A ponteira de aplicação do laser era introduzida via transvaginal, fixada a um cabo de policloreto de vinila, emitindo-se as ondas pelo fundo de saco vaginal. Após a realização do toalete vulvar, a seco, ambos os ovários, um de cada vez, eram direcionados à supracitada ponteira do aparelho, com auxílio da "pega" do ovário, via transretal, possibilitando a permanência do ovário na direção do diodo laser durante a aplicação da luz (FIGURA 1). 


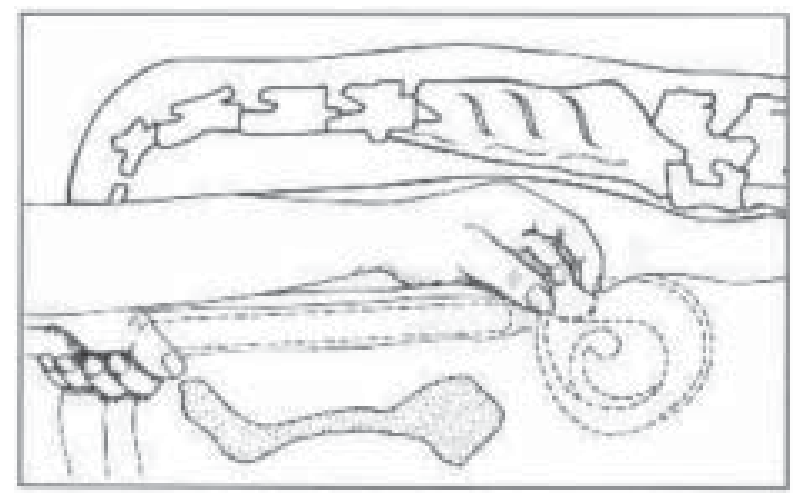

FIGURA 1 - Demonstração da técnica realizada para o tratamento com laserterapia sobre o ovário bovino

Figure 1 - Demonstration of the procedure performed for the lasertherapy in bovine ovary

Fonte: Adaptado de Bluhm (2006)

TABELA 1 - Protocolo de tratamento com leserterapia realizado até a reversão do anestro puerperal em vaca da raça holandesa preta e branca em amamentação, Fazenda Rio Grande (PR), 2007

Table 1 - Lasertherapy treatment protocol, performed until anestrus puerperal reversion, in black and white Holstein cow in lactation, Fazenda Rio Grande (PR), 2007

\begin{tabular}{lccc}
\hline Aplicaçâo & Dose $\left(\mathrm{j} / \mathrm{cm}^{2}\right)$ & Potència (mw) & Tempo de aplicaçĩo (seg.) \\
\hline $1^{\circ}$ & 2 & 50 & 40 \\
$2^{\circ}$ & 2 & 50 & 40 \\
$3^{\circ}$ & 2 & 50 & 40 \\
$4^{\circ}$ & 2 & 50 & 40 \\
$5^{\circ}$ & 2 & 50 & 40 \\
$6^{\circ}$ & 2 & 50 & 40 \\
$7^{\circ}$ & 2 & 50 & 40 \\
$8^{\circ}$ & 2 & 50 & 40 \\
$9^{\circ}$ & 4 & 50 & 40 \\
$10^{\circ}$ & 4 & 50 & 40 \\
$11^{\circ}$ & 4 & 50 & 40 \\
$12^{\circ}$ & 4 & 50 & 40 \\
$13^{\circ}$ & 4 & 50 & 40 \\
$14^{\circ}$ & 4 & 50 & 40 \\
\hline
\end{tabular}

Obs.: Estro no $14^{\circ}$ dia de aplicação. No período compreendido entre a $7^{\circ}$ e $8^{\circ}$ aplicação, o animal não recebeu tratamento devido a problemas técnicos no aparelho. O primeiro dia de aplicação correspondeu ao $59^{\circ}$ dia pós-parto do animal em anestro, seguindo a ordem cronológica até o final do protocolo. 


\section{RESULTADOS E DISCUSSÃO}

Nas Figuras 2 a 5 podem ser observadas as ultra-sonografias dos ovários no decorrer do tratamento com laserterapia.

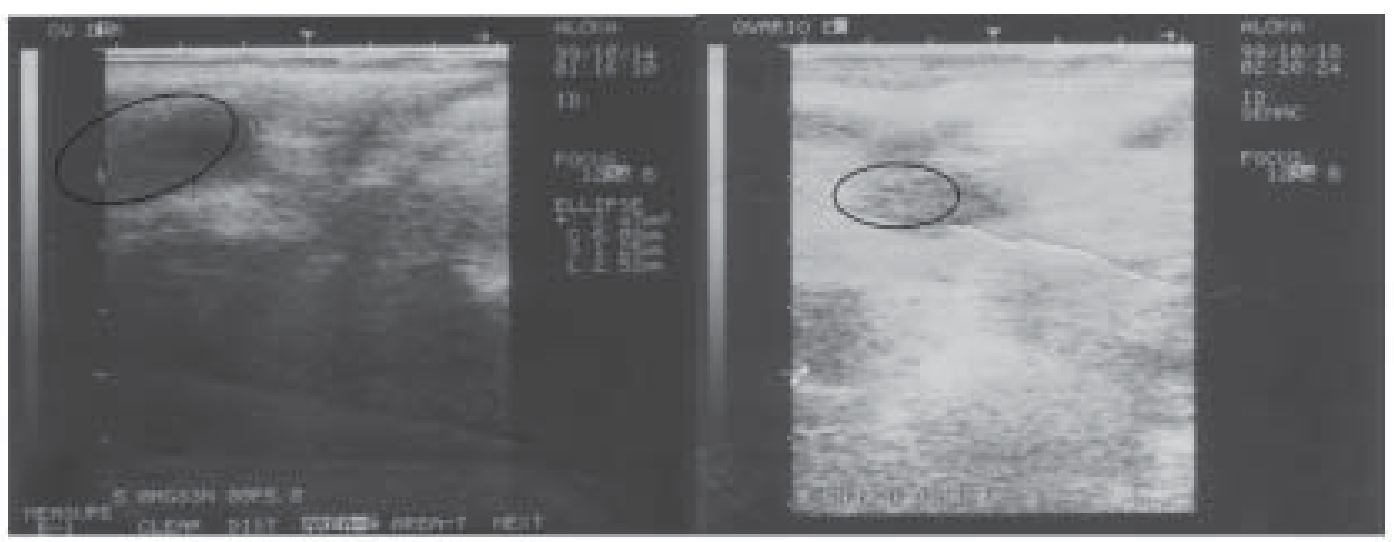

FIGURA 2 - Ultra-sonografia do ovário direito e esquerdo de bovino, sem atividade ovariana (ausência de folículo e corpo lúteo) no anestro puerperal com 56 dias anterior à laserterapia, escore de condição corporal de 1,5 Fazenda Rio Grande, PR - 2007

Figure 2 - Left and right bovine ovary ultrasound image, without ovarian activity (absence of folicule and corpus luteum) under 56 days of anestrus puerperal prior to the lasertherapy, corporal score 1,5 - Fazenda Rio Grande, PR - 2007
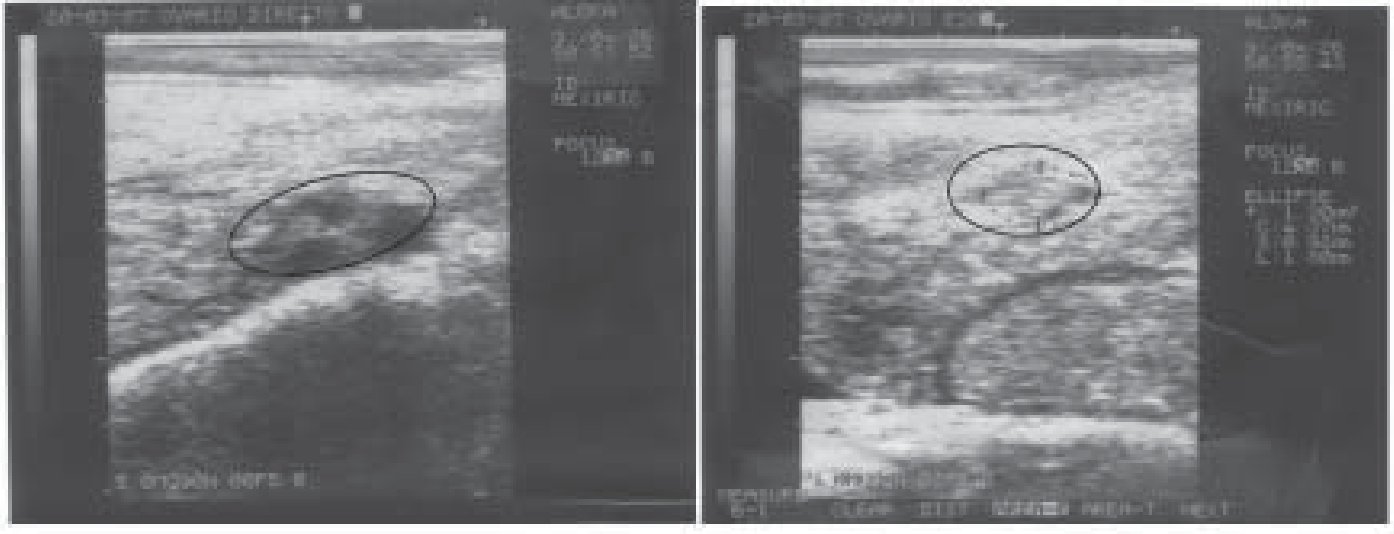

FIGURA 3 - Ultra-sonografia do ovário direito e esquerdo de bovino, no anestro puerperal com 74 dias, no $8^{\circ}$ dia de aplicação da laserterapia, escore de condição corporal de 1,5 - Fazenda Rio Grande, PR - 2007

Figure 3 - Left and right bovine ovary ultrasound image, under 74 days of anestrus puerperal, in the $8^{\text {th }}$ day of lasertherapy, corporal score 1,5 - Fazenda Rio Grande, PR - 2007

Obs.: Observa-se a presença de folículos à ultra-sonografia. 


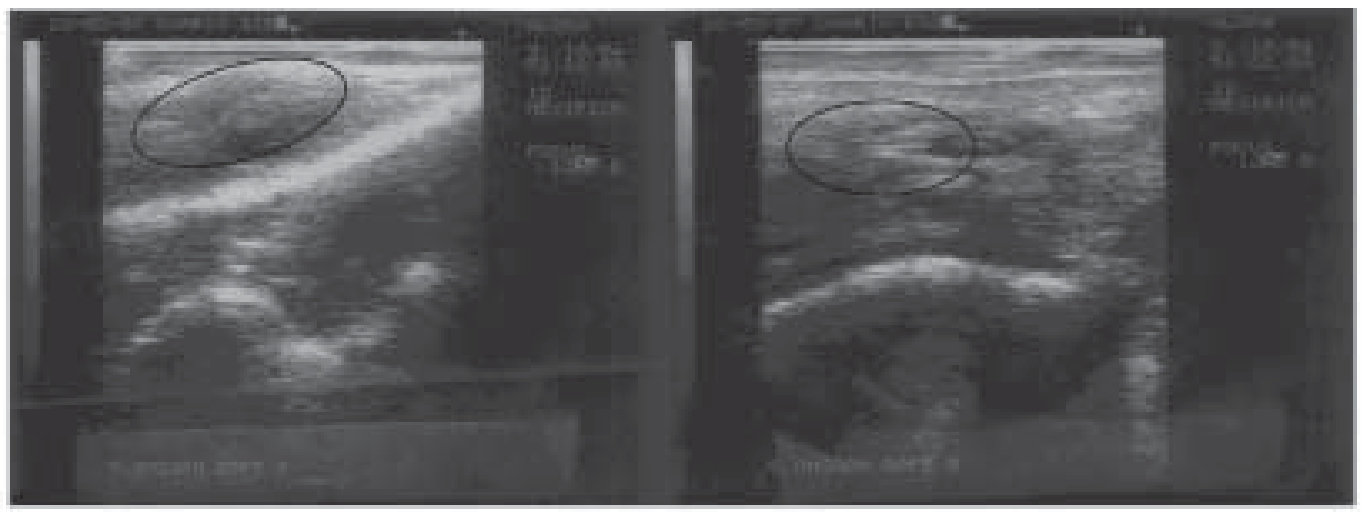

FIGURA 4 - Ultra-sonografia do ovário direito e esquerdo de bovino, no $14^{\circ}$ dia de aplicação da laserterapia, escore de condição corporal de 1,5 Fazenda Rio Grande, PR - 2007

Figure 4 - Left and right bovine ovary ultrasound image, in the $14^{\circ}$ day of lasertherapy, corporal score 1,5 - Fazenda Rio Grande, PR - 2007

Obs.: No $14^{\circ}$ dia com estro visível, reflexo de tolerância associado a muco límpido e cristalino presentes à ultra-sonografia corpus hemorragicum no ovário direito.

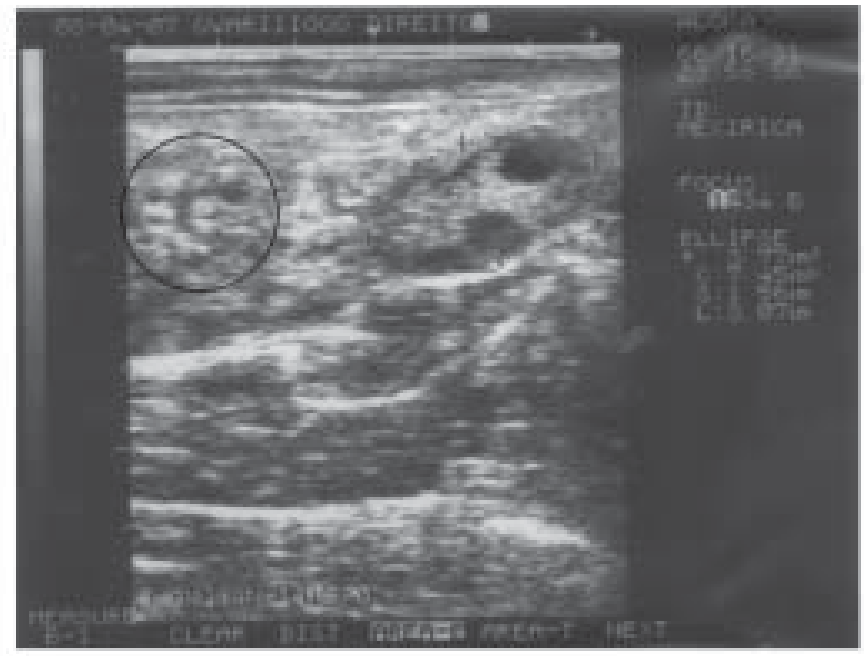

FIGURA 5 - Ultra-sonografia do ovário direito de bovino, no $12^{\circ}$ dia pós-estro, presença de corpo lúteo, escore de condição corporal de 1,5-Fazenda Rio Grande, PR - 2007

Figure 5 - Right bovine ovary ultrasound image, in the $12^{\circ}$ post estrus, with corpus luteum present, corporal score 1,5 - Farm Rio Grande, PR - 2007 
A infertilidade e o anestro pós-parto nos bovinos são problemas provenientes de vários fatores que atuam individual ou conjuntamente, acarretando redução do seu potencial reprodutivo. Muitos desses fatores não podem ser eliminados, mas devem ser considerados na tomada de decisões de manejo, com vistas a outros fatores passíveis de manipulação. Especificamente, o anestro pós-parto é um contribuinte de significativa importância para a infertilidade de um rebanho e, nesse aspecto, necessitase de uma clara noção da influência da lactação em si, sobre a supressão da atividade ovariana e também sobre o plano nutricional, nas funções endócrinas e no trato genital. A presença do bezerro-ao-pé da mãe, como ocorre no manejo tradicional, amamentando diuturnamente, exerce um efeito negativo sobre o retorno dos animais à atividade reprodutiva, prolongando demasiadamente o período de serviço e diminuindo a taxa de eficiência reprodutiva (SEGUI et al., 2002). A eficiência reprodutiva é o fator mais importante para o produtor rural, uma vez que o atraso na concepção de uma fêmea bovina reduz o rendimento e aumenta o custo final de produção (PINTO; LUCENA, 1999).

As mudanças da hemodinâmica envolvidas no remodelamento cíclico das estruturas ovarianas, o desenvolvimento folicular e a ovulação são dependentes de uma rede microcirculatória funcional sobre a camada da teca interna do folículo pré-ovulatório, ao desenvolver uma rede fina de capilares, que alcançam a proximidade da camada granulosa. O aumento no fluxo do sangue sobre a camada da teca do folículo dominante resulta em uma fonte aumentada de gonadotrofinas e de outros fatores bioquímicos sistêmicos e hormonais necessários para o desenvolvimento folicular (ACOSTA; MIYAMOTO, 2004).

\section{CONCLUSÕES}

Com base nesses estudos, a laserterapia demonstrou ter aplicações benéficas, ao detectar-se inatividade cíclica ovariana no bovino. No presente experimento, o animal tratado encontrava-se em anestro. O tratamento à base de emissões de luz laser infravermelha aumentou, mediante seus efeitos, a irrigação sanguínea no estroma ovariano, de modo a desenvolver folículos e um folículo dominante responsável pelos sinais de estro após 14 aplicações, comprovado com o acompanhamento ultrasonográfico dos ovários (FIGURAS 2, 3, 4 e 5), palpação transretal e receptividade ao touro. A laserterapia de baixa potência apresentou resultados favoráveis no tratamento do anestro puerperal, ao acarretar no animal sinais externos de cio e reflexo de tolerância à monta. Os dados obtidos são fortes indícios para concluir-se que o emprego da laserterapia sobre o estroma ovariano proporcionou maior atividade ovariana nos ovários bovinos, manifestado pelo desenvolvimento de folículo dominante e sinais externos de cio.

O presente experimento foi demonstrado pela primeira vez nos moldes aqui propostos. Evidentemente faltam dados a respeito na literatura mundial. Essa pesquisa, portanto, mostrou-se pioneira em função à absoluta escassez de referências. Assim, sugere-se que outros trabalhos de cunho científico sejam efetuados para aprimorar-se a eficácia da laserterapia e comprovar seus efeitos sobre os ovários.

\section{REFERÊNCIAS}

ACOSTA, T. J.; MIYAMOTO, A. Vascular control of ovarian function: ovulation, corpus luteum formation and regression. Animal Reproduction Science, Japão, v. 82-83, p. 127-140, 2004.

BAXTER, D. Laserterapia de baixa potência. In: KITCHEN, S.; BAZIN, S. Eletroterapia de Clayton. São Paulo: Manole, 1998. p. 192-197.

BLUHM, C. A. Biotechnology techniques for gamets and embriyos: recovery of embriyos. 2006 Disponível em: <http://users.netonecom.net/ maplevcew/cattle/ images/diagram.jpg>. Acesso em: 15 Feb. 2006. 
CARCI INDUSTRIA E COMÉRCIO DE APARELHOS CIRÚRGICOS E ORTOPÉDIOCS LTDA Lasermed 4090 Manual do usuário, São Paulo, p. 1-35, 2003. Disponível em: <http:// www.carci.com.br>. Acesso em: 05 fev. 2007.

EDMONDSON, A. J.; LEAN, I. J.; WEAVER, L. D. A body condition scoring chat for hostein dairy cows. Journal of Dairy Science, Savoy, v. 72, p. 68-78, 1989.

MALDONADO, E. P. Mecanismos de interação laser: tecido. Universidade de São Paulo, USP: [s. n.], 2003. Apostila.

PINTO, N. F.; LUCENA, A. J. M. Causas do anestro pós-parto prolongado em vacas leiteiras cruzadas. Revista do Conselho Federal de Medicina Veterinária, São Paulo, v. 5, n.18, p. 10-13, 1999.

SEGUI, M. S. et al. Indução ao estro em bovinos de corte. Archives of Veterinary Science, Curitiba, v. 7, n. 2, p. 173-174, 2002.

VEÇOSO, M. C. Laser em fisioterapia. São Paulo: Lovise, 1993.

Recebido em: 22/10/2006

Received in: $10 / 22 / 2006$

Aprovado em: 30/03/2007

Approved in: 03/30/2007 